\title{
métodos de Controle de Plantas Daninhas e Desrama Precoce no CRescimento do Eucalipto em Sistema Silvipastoril ${ }^{1}$
}

\author{
The Effect of Weed Control and Early Pruning Methods on Eucalyptus Growth under the \\ Silvopastoral System
}

\author{
MACHADO, M.S. ${ }^{2}$, FERREIRA, L.R. ${ }^{2}$, OLIVEIRA NETO, S.N. ${ }^{2}$, FERREIRA, G.L. ${ }^{2}$, FONTES, D.R. ${ }^{2}$ e \\ MACHADO, A.F.L. ${ }^{3}$
}

\begin{abstract}
RESUMO - Objetivou-se neste trabalho avaliar os efeitos da capina química e mecânica e da desrama precoce sobre o crescimento do eucalipto em sistema silvipastoril, composto por Eucalyptus saligna (9 × $3 \mathrm{~m}$ ) e Brachiaria brizantha. Os tratamentos constaram de um fatorial $5 \times 2$, sendo cinco niveis de desrama $(0,10,20,30$ e 40\% da altura de copa viva do eucalipto) e dois tipos de coroamento: capina mecânica e química. Foram avaliados o ganho em altura, diâmetro ao nível do solo e volume de copa aos 90, 180, 270 e 360 dias após aplicação dos tratamentos (DAA). Aos 640 DAA, avaliou-se o crescimento em diâmetro e altura, bem como a matéria seca do tronco. Diferenças significativas não foram observadas nos parâmetros avaliados em função dos métodos de capina, porém houve efeito para a intensidade de desrama e época de avaliação. Em todas as épocas avaliadas, o aumento no nível de desrama proporcionou redução no crescimento das plantas. Aos 90 DAA, plantas com 40\% de desrama apresentaram redução no crescimento em altura de 69\% e de $87 \%$ para diâmetro, em relação às plantas não desramadas; aos 360 DAA, essa diferença caiu para 21,8 e 22,8\% para altura e diâmetro, respectivamente. Aos 640 DAA, observaram-se indicativos de recuperação das plantas desramadas; entretanto, ainda foram verificados efeitos negativos da intensidade de desrama sobre o crescimento do eucalipto. Conclui-se que o tipo de capina não influenciou o crescimento inicial do eucalipto e que a desrama precoce facilita a aplicação de glyphosate, porém causa redução no crescimento das plantas.
\end{abstract}

Palavras-chave: sistemas agroflorestais, matocompetição, glyphosate.

\begin{abstract}
The objective of this work was to evaluate the effects of chemical and mechanical weeding and pruning on the early growth of eucalyptus under the silvopastoral system, consisting of Eucalyptus saligna (clone 34039), spaced $9 \times 3 \mathrm{~m}$ and Brachiaria brizantha. The treatments consisted of a $5 \times 2$ factorial, with five levels of pruning: 0, 10, 20, 30 and 40\% live crown and two types of eucalyptus crown, mechanical and chemical weeding. The following parameters were evaluated: Gain in height, diameter at ground level and canopy volume at 90, 180, 270 and 360 days after application (DAA), and at 640 DAA, growth in diameter and height, and stem dry matter. There were no significant differences for the parameters evaluated for the weeding methods. However, there was no effect for the intensity of pruning and time of evaluation. In all periods, the increase in the level of pruning caused a reduction in growth in height and diameter. At $90 \mathrm{DAA}, 40 \%$ of the pruned plants showed a reduction in height growth of $69 \%$ and $87 \%$ for diameter, compared to plants not pruned, and, at $360 \mathrm{DAA}$, with this difference falling to 21.8 and $22.8 \%$ for height and diameter, respectively. At 640 DAA, indication of recovery of the pruned plants was observed but no negative effects of pruning intensity on the growth of eucalyptus were found. It was concluded that the type of weeding did not influence the early growth of eucalyptus and early pruning facilitates glyphosate application, but causes plant growth reduction.
\end{abstract}

Keywords: agroforestry, weed competition, Glyphosate.

1 Recebido para publicação em 27.6.2013 e aprovado em 8.9.2013.

2 Universidade Federal de Viçosa, Viçosa-MG, Brasil, <milermachado@yahoo.com.br>; ${ }^{3}$ Universidade Federal Rural do Rio de Janeiro, Rio de Janeiro-RJ, Brasil.

Planta Daninha, Viçosa-MG, v. 32, n. 1, p. 133-140, 2014 


\section{INTRODUÇÃO}

Espaçamentos de plantio mais amplos e espécies florestais com copas que favorecem a passagem de radiação solar são estratégias de manejo importantes para os sistemas agrossilvipastoris e silvipastoris. Nessas condições, verifica-se maior disponibilidade de radiação solar no sub-bosque, favorecendo a competitividade e o crescimento de espécies forrageiras, bem como a maior infestação de plantas daninhas. Assim, o controle da matocompetição torna-se essencial e necessário para atingir satisfatórios niveis de produção nesses sistemas.

Entre os métodos de controle de plantas daninhas empregados na cultura do eucalipto, o uso de herbicidas tem sido o mais utilizado, devido à escassez de mão de obra e ao menor custo; entretanto, ainda é comum o uso da capina mecânica, principalmente em pequenas propriedades rurais. O glyphosate é o herbicida mais utilizado, por exercer bom controle de grande número de espécies daninhas mono e dicotiledôneas, perenes e anuais. Todavia, é comum a ocorrência de deriva do glyphosate durante as aplicações, que atingem principalmente os ramos mais baixos das plantas, provocando, com frequência, intoxicações nas plantas de eucalipto (Tuffi Santos et al., 2007). O contato do glyphosate pode causar prejuízos ao crescimento do eucalipto ou mesmo a diminuição do estande, devido à morte de plantas mais jovens (Tuffi Santos et al., 2005).

Em razão da importância do glyphosate nos plantios florestais e dos inúmeros prejuízos causados por sua deriva, existe a necessidade de desenvolver e implementar tecnologias que facilitem a aplicação desse herbicida, reduzindo os danos causados ao eucalipto. Nesse sentido, a retirada dos galhos mais baixos através da desrama precoce pode reduzir, ou até mesmo eliminar, a intoxicação por glyphosate em plantas de eucalipto.

A desrama artificial é uma prática silvicultural recomendada para melhoria da qualidade da madeira de árvores manejadas para produção de madeira de qualidade para serraria e laminação. Ela favorece a produção de madeira limpa, livre de nós, desde que ocorra cicatrização completa dos ferimentos, o que irá depender do diâmetro do galho, da sua localização no tronco, do vigor da planta, da idade de realização e da qualidade da operação da desrama artificial (Pires, 2000; Pulrolnik et al., 2005). Caso essa prática seja realizada precocemente, ela poderá tornar mais simples a aplicação de herbicida, em razão da retirada de ramos e folhas na parte inferior da copa, evitando possíveis injúrias causadas por herbicidas.

Estudos indicam que a desrama artificial pode não influenciar o crescimento das árvores quando o material genético tem capacidade de recompor sua área foliar ou quando a remoção de área foliar é reduzida e constituída, principalmente, de folhas basais, que já se encontram em senescência (Almeida, 2003; Lima, 2003).

Monte et al. (2009), avaliando o crescimento de Eucalyptus grandis submetido a diferentes intensidades e frequências de desrama artificial, iniciadas aos 400 dias após o plantio, verificaram que a intensidade e frequência da desrama artificial não causaram prejuízos ao crescimento do eucalipto, devendo-se evitar remoção superior a $60 \%$ da biomassa foliar total para obter madeira de maior diâmetro. Pulrolnik et al. (2005), avaliando a capacidade de crescimento das plantas de Eucalyptus grandis em resposta à aplicação de diferentes intensidades e idades de aplicação de desrama, verificaram que por volta dos 20 meses de idade é a melhor época para a aplicação da desrama, visando obter madeira de melhor qualidade para serraria. Embora alguns estudos tenham mostrado que a desrama não interfere no crescimento do eucalipto, se a remoção dos ramos for realizada de forma precoce e drástica, haverá retirada de folhas da porção mediana da copa, com elevada capacidade fotossintética (Beadle et al., 2007), podendo reduzir o crescimento das plantas (Pires et al., 2002; Pinkard et al., 2003).

Diante do exposto, propôs-se, com este trabalho, avaliar os efeitos da capina química e mecânica e da desrama precoce sobre o crescimento do eucalipto em sistema silvipastoril.

\section{MATERIAL E MÉTODOS}

Este trabalho foi desenvolvido em campo, no município de Viçosa, Minas Gerais, nas 
coordenadas de $20^{\circ} 75^{\prime} \mathrm{S}$ e $42^{\circ} 88^{\prime} \mathrm{W}$, em altitude de $650 \mathrm{~m}$. O clima é tropical de altitude, com verão chuvoso e inverno frio e seco, do tipo Cwb pelo sistema de Köppen (Golfari, 1975).

O experimento foi realizado numa área de sistema silvipastoril, 300 dias após a implantação da pastagem. O plantio do Eucalyptus saligna (clone 34039) foi realizado após dessecação da área com glyphosate $+2,4-\mathrm{D}$, em covas de 0,3 0 0,3 x 0,3 m, no espaçamento de 9 x 3 m (370 plantas ha $\left.{ }^{-1}\right)$, consorciado com braquiária. Foram aplicados $130 \mathrm{~g}$ por cova da formulação N-P-K (06-30-06) + 1\% de boro no plantio do eucalipto e duas adubações de cobertura, uma aos 90 dias após o plantio, com a aplicação de $150 \mathrm{~g}$ da formulação N-P-K (2005-20), e outra aos 360 dias após o plantio, aplicando-se $150 \mathrm{~g}$ de $\mathrm{KCl}+$ boro. A semeadura de Brachiaria brizantha foi feita 90 dias após o plantio do eucalipto, com máquina específica para plantio a lanço, sem adubação, numa densidade de $6 \mathrm{~kg} \mathrm{ha}^{-1}$ de sementes, com valor cultural de $72 \%$.

Utilizou-se o delineamento de blocos ao acaso com quatro repetições, no esquema fatorial $5 \times 2$, sendo cinco niveis de desrama $(0,10,20,30$ e $40 \%$ da altura de copa viva do eucalipto) e dois tipos de coroamento: capina mecânica e química com glyphosate. As parcelas foram compostas por cinco plantas, sendo três destas utilizadas para coleta dos dados. Ao lado de cada parcela havia uma linha de plantio, como bordadura.
Após a demarcação das parcelas e antes da aplicação dos tratamentos, 300 dias após o plantio, foram feitas medições de diâmetro ao nível do solo e da altura de cada planta na área útil das parcelas. Por ocasião da mensuração inicial, as plantas apresentavam, em média, altura de 3,11 m e 4,47 cm de diâmetro.

A desrama artificial foi realizada em relação à altura de copa viva da árvore, ou seja, altura entre a inserção do primeiro galho vivo e o ápice da planta, retirando-se todos os galhos abaixo do ponto determinado para cada tratamento (Tabela 1).

As aplicações do glyphosate ( $1.080 \mathrm{~g}$ e.a. $\mathrm{ha}^{-1}$ ) foram realizadas visando ao controle de Brachiaria brizantha e outras plantas daninhas num raio de $1,0 \mathrm{~m}$ ao redor do caule do eucalipto, tomando-se os devidos cuidados para se evitar a deriva do herbicida nas folhas. Foi utilizado pulverizador costal manual munido de um bico TTI 110015 , com válvula reguladora de pressão de $300 \mathrm{KPa}$, aplicando um volume de calda de $150 \mathrm{~L} \mathrm{ha}^{-1}$.

Os coroamentos mecânicos foram realizados através de capina com enxada, no raio de $1,0 \mathrm{~m}$ ao redor do caule do eucalipto. Foram realizadas quatro aplicações de herbicidas e quatro coroamentos com enxadas, aos 0,60 , 150 e 300 dias após a aplicação dos tratamentos (DAA), visando eliminar a competição das plantas daninhas e de Brachiaria brizantha com o eucalipto durante o período de condução do experimento.

Tabela 1 - Tipo de capina, intensidade de desrama e altura de inserção da copa antes e após a desrama

\begin{tabular}{|l|c|c|c|c|c|}
\hline \multirow{2}{*}{ Tipo de capina } & $\begin{array}{c}\text { Intensidade de } \\
\text { desrama }(\%)\end{array}$ & $\begin{array}{c}\text { Altura da copa viva } \\
(\mathrm{m})\end{array}$ & $\begin{array}{c}\text { Altura da desrama } \\
(\mathrm{m})\end{array}$ & \multicolumn{2}{|c|}{ Inserção do primeiro ramo vivo (m) } \\
\cline { 4 - 6 } & 0 & 3,0 & 0,00 & Antes da desrama & Após a desrama \\
\hline Mecânica & 0 & 2,7 & 0,00 & 0,30 & 0,30 \\
\hline Química & 10 & 2,7 & 0,27 & 0,29 & 0,29 \\
\hline Mecânica & 10 & 2,9 & 0,29 & 0,28 & 0,55 \\
\hline Química & 20 & 2,9 & 0,59 & 0,28 & 0,57 \\
\hline Mecânica & 20 & 2,7 & 0,55 & 0,30 & 0,87 \\
\hline Química & 30 & 2,7 & 0,81 & 0,28 & 1,09 \\
\hline Mecânica & 30 & 2,9 & 0,86 & 0,29 & 1,16 \\
\hline Química & 40 & 3,0 & 1,19 & 0,29 & 1,47 \\
\hline Mecânica & 40 & 2,7 & 1,08 & 0,29 & 1,37 \\
\hline Química & & & 0.29 & \\
\hline
\end{tabular}


Foram avaliados os sintomas de intoxicação pelo glyphosate nas plantas de eucalipto, aos 10,70, 160 e 310 DAA, o ganho em altura da planta e diâmetro ao nível do solo e o volume de copa viva. O ganho em altura e diâmetro foi calculado pela diferença entre a avaliação realizada nas épocas $(90,180,270$ e 360 DAA) e aquela aos 0 DAA. A altura das plantas foi medida utilizando-se uma baliza graduada, e o diâmetro, um paquímetro. $\mathrm{O}$ volume $\left(\mathrm{m}^{3}\right)$ de copa viva das plantas foi estimado através da fórmula proposta por Turrell (1946) citado por Santos et al. (1998):

$$
\text { Volume }(V)=\frac{\pi D^{2}}{12} \times H
$$

em que $D$ é o diâmetro médio basal da copa (m) e $H$ a altura da copa viva da planta (m). O diâmetro médio $(D)$ foi obtido a partir de duas medidas na parte basal da copa das plantas, sendo uma no sentido do maior diâmetro e outra perpendicularmente à primeira.

Os dados relativos de ganho em diâmetro ao nivel do solo, da altura e de volume de copa viva foram analisados como um fatorial $5 \times 2$ em parcelas subdivididas no tempo (quatro épocas de avaliação: 90, 180, 270 e 360 DAA).

Aos 640 DAA, uma planta com dimensão média, de cada parcela, foi abatida a aproximadamente $5 \mathrm{~cm}$ do solo, e foram realizadas medidas de diâmetro e altura do tronco (até $2 \mathrm{~cm}$ de diâmetro). Amostras de discos do tronco de aproximadamente $5 \mathrm{~cm}$ de espessura foram coletadas da região basal, mediana e do topo, para determinação da matéria seca. Essas amostras foram acondicionadas em sacos de papel e mantidas em estufa com circulação de ar a $75{ }^{\circ} \mathrm{C}$, até atingirem peso constante.

Os dados foram submetidos à análise de variância e regressão. Os modelos foram escolhidos com base no fenômeno biológico, na significância dos coeficientes de regressão, utilizando o teste $\mathrm{t}$ e adotando-se o nivel de $5 \%$ de probabilidade, e no coeficiente de determinação $\left(R^{2}\right)$.

\section{RESULTADOS E DISCUSSÃO}

Não se observou efeito significativo $(P<0,05)$ para o tipo de capina, porém verificou-se efeito da desrama, de épocas de avaliação, bem como a interação época $\mathrm{x}$ desrama, no crescimento em altura, diâmetro e volume de copa das plantas de eucalipto.

O nivel de intoxicação das plantas pelo glyphosate foi baixo mesmo nas plantas sem desrama (Figura 1), diferentemente do observado em campo por Tuffi Santos et al. (2007).

Para avaliar o efeito intensidade da desrama, os dados de ganho em altura de plantas, em diâmetro ao nível do solo e volume de copa foram analisados mediante equações de regressão múltipla. As superfícies de resposta (Figuras 2, 3 e 4) resultantes das equações evidenciam os efeitos da intensidade de desrama e da época de avaliação.

Verificou-se relação linear negativa para a intensidade de desrama; o aumento na intensidade proporcionou redução no crescimento das plantas, em todas as variáveis analisadas. Aos 90 DAA, plantas sem desrama apresentaram maior ganho em altura $(2,17 \mathrm{~m})$. Nessa época, as plantas submetidas a $40 \%$ de desrama mostraram ganho médio de $0,68 \mathrm{~m}$, representando apenas $31 \%$ do ganho máximo (Figura 2).

Para o diâmetro, observou-se aos 90 DAA que as plantas não desramadas apresentaram ganho em diâmetro de $1,81 \mathrm{~cm}$, e as submetidas a 10,20, 30 e 40\% de desrama apresentaram, respectivamente, $1,41,1,02,0,62 \mathrm{e}$

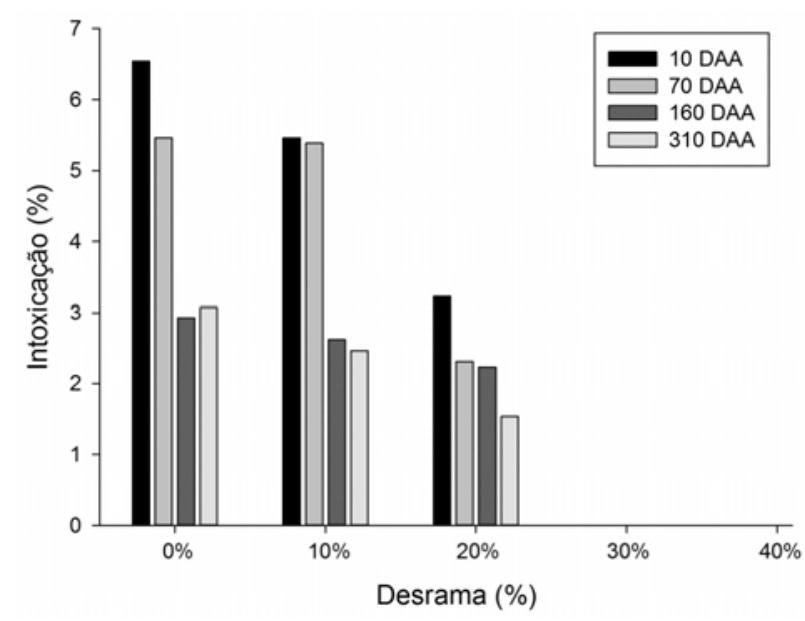

Figura 1 - Intoxicação pelo glyphosate aplicado no entorno das plantas de eucalipto submetidas a diferentes níveis de desrama precoce, em diferentes épocas de avaliação em sistema silvipastoril. 
$\hat{\mathrm{A}}=0,6204-0,0374 " \mathrm{D}+0,0172 " \mathrm{~T} \quad \mathrm{R}^{2}=0,9519$

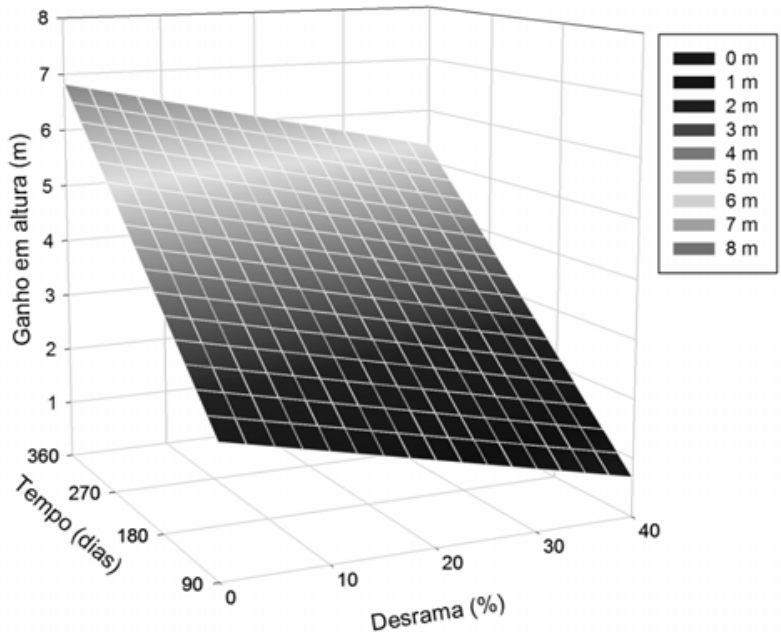

Figura 2 - Estimativa do crescimento em altura de plantas de eucalipto em sistema silvipastoril submetidas a desrama precoce ao longo do tempo.

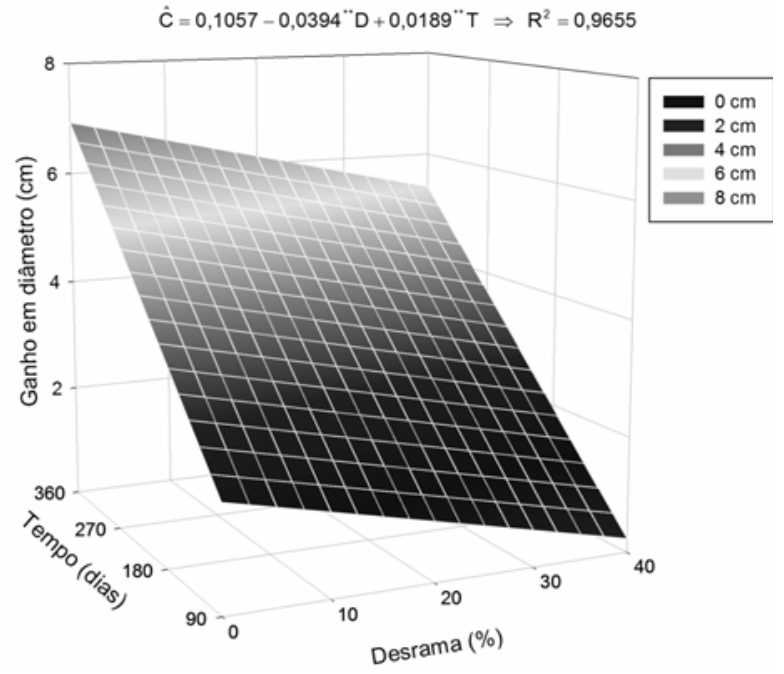

Figura 3 - Estimativa do ganho em diâmetro ao nível do solo de plantas de eucalipto submetidas a desrama precoce em sistema silvipastoril ao longo do tempo.

$0,23 \mathrm{~cm}$ de diâmetro, ou seja, uma redução de $21,8,43,6,65,4$ e $87,2 \%$, respectivamente, em relação às plantas não desramadas (Figura 3). Em todas as épocas avaliadas, o crescimento em diâmetro foi superior nas plantas sem desrama, comportando-se em ordem inversa com a intensidade de desrama. Entretanto, aos 360 DAA, notou-se a tendência de recuperação do crescimento das plantas desramadas, sendo

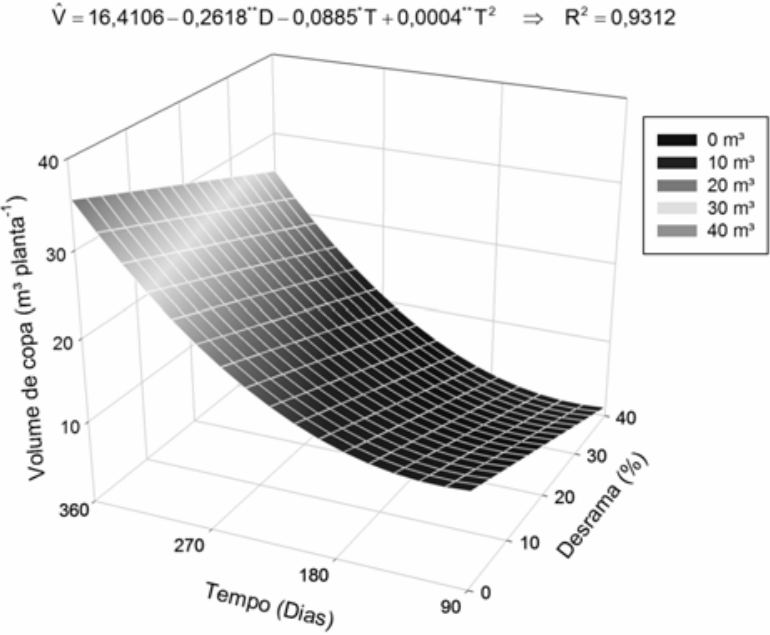

Figura 4 - Estimativa do volume de copa de plantas de eucalipto no sistema silvipastoril submetidas a diferentes intensidades de desrama precoce ao longo do tempo.

de $5,7,11,4,17,1$ e $22,8 \%$ as diferenças entre as plantas com 10, 20, 30 e 40\% de desrama, respectivamente, em relação à testemunha (Figura 3).

Os volumes de copa estimados aos 90 DAA para as plantas com $0,10,20,30$ e $40 \%$ de desrama foram $11,7,9,1,6,4,3,8$ e $1,2 \mathrm{~m}^{3}$, respectivamente, ao passo que aos 360 DAA esses volumes foram de 36,4, 33,8, 31,1, 28,5 e 25,9 (Figura 4). Esses valores também evidenciam a tendência de recuperação do volume de copa das plantas desramadas.

Aos 640 DAA, observou-se efeito significativo $(\mathrm{P}<0,05)$ para diâmetro, altura e matéria seca do tronco, em função da intensidade de desrama. O tipo de capina e a interação capina $\mathrm{x}$ desrama não apresentaram efeitos significativos. Nessa idade, a altura máxima estimada do tronco das plantas de eucalipto foi observada nas plantas sem desrama: 11,67 m (Figura 5).

Comparando o diâmetro estimado aos 640 DAA nas diferentes intensidades de desrama, observa-se que 10, 20, 30 e $40 \%$ proporcionaram redução de $7,1,14,2,21,4$ e $28,5 \%$, respectivamente, em relação à testemunha sem capina (Figura 6).

A produção de matéria seca do tronco acompanhou a tendência dos crescimentos em diâmetro e altura, com valores mais 


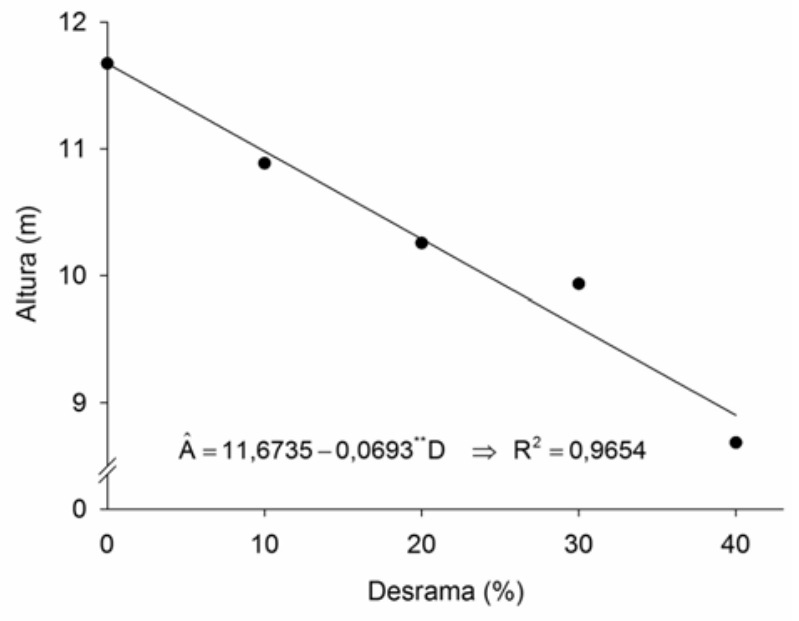

Figura 5 - Estimativa da altura do tronco de plantas de eucalipto em sistema silvipastoril, em função de diferentes intensidades de desrama precoce, aos 640 dias após implantação dos tratamentos.

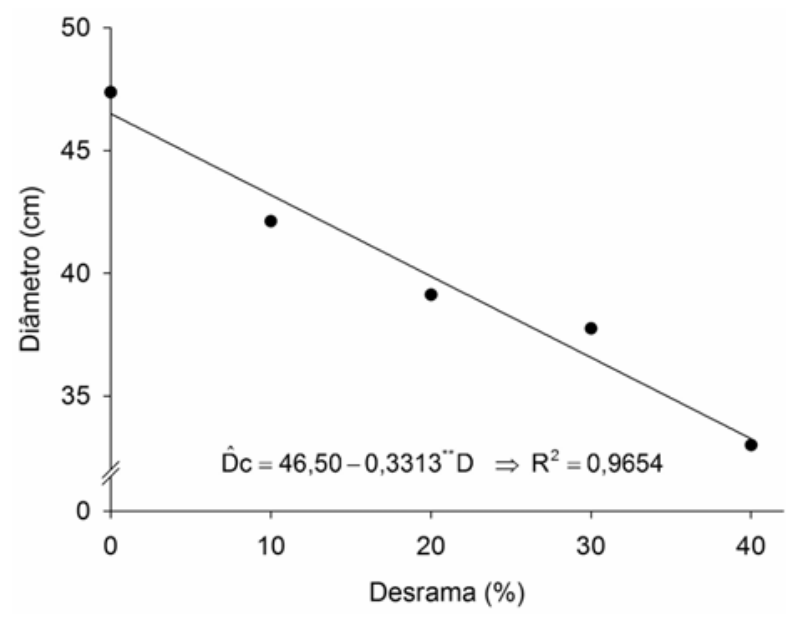

Figura 6 - Estimativa do crescimento do diâmetro ao nível do solo de plantas de eucalipto em sistema silvipastoril, em função de diferentes intensidades de desrama precoce, aos 640 dias após implantação dos tratamentos.

elevados para a testemunha, decrescendo com a intensidade de desrama (Figura 7). A testemunha apresentou produção de 34,49 kg por planta, e as plantas com 40\% de desrama, apenas $15,26 \mathrm{~kg}$ por planta, representando uma redução de 56\% (Figura 7).

O controle mecânico de plantas daninhas com uso da enxada tem como principal vantagem não intoxicar as plantas, o que pode ocorrer em aplicações incorretas de herbicidas. A maior limitação do controle mecânico, principalmente em áreas mais extensas, é a

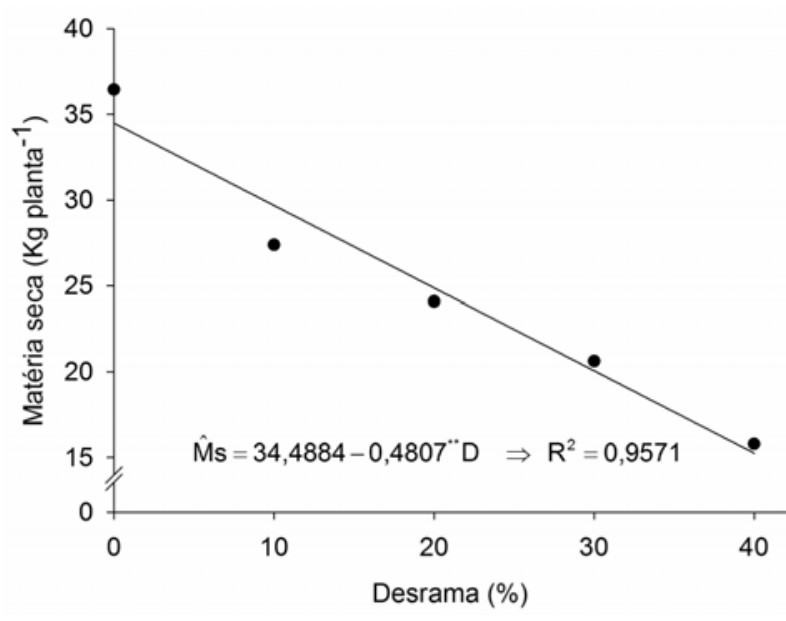

Figura 7 - Estimativa da matéria seca do tronco de plantas de eucalipto em sistema silvipastoril, em função de diferentes intensidades de desrama precoce, aos 640 dias após implantação dos tratamentos.

dificuldade de encontrar mão de obra no momento necessário e na quantidade desejada (Machado et al., 2010). Outro fator limitante ao uso da capina mecânica nos sistemas silvipastoris é a capacidade de rebrota da braquiária, possibilitando a reinfestação da área por plantas cortadas superficialmente (Chiovato et al., 2007).

O fato de não haver diferenças significativas para os tipos de capina mostra que a aplicação de herbicidas pode ser tão eficiente e segura quanto a capina com enxada, desde que realizada por profissionais devidamente treinados para esse fim. Contudo, deve-se ressaltar que a aplicação do glyphosate neste experimento foi realizada tomando-se os devidos cuidados para se evitar a deriva do herbicida para as folhas do eucalipto. Mesmo com cautela, é comum o jato de aplicação atingir diretamente os ramos baixeiros das plantas, sendo essa forma de contato considerada a principal causa de intoxicação das plantas (Tuffi Santos et al., 2010).

Tuffi Santos et al. (2007), avaliando os efeitos da deriva de glyphosate no crescimento e na produção de eucalipto (híbrido urograndis), relataram que plantas com porcentagem de intoxicação de $21-30 \%$ reduziram em $18 \%$ a produção de madeira em relação àquelas não afetadas pelo glyphosate, aos 360 DAA. 
Por se tratar de um herbicida sistêmico, que atua em regiões meristemáticas das plantas, a intoxicação por glyphosate pode causar, em função da quantidade de produto que atinge a planta, a morte do ápice caulinar (Tuffi Santos et al., 2005), o que pode provocar a bifurcação da planta e a diminuição da produção e da qualidade da madeira.

Em relação à desrama, observou-se, para todas as características avaliadas, a limitação do crescimento do eucalipto com o aumento da intensidade da desrama. Entretanto, caso não seja muito severa, os efeitos das desramas tendem a desaparecer com o tempo (Endo \& Mesa, 1992). Pires (2000) observou que, aos sete anos de idade, a desrama (11 meses após o plantio) de 12,5, 25, 50 e 75\% de intensidade, em E. grandis, reduziu significativamente o crescimento em diâmetro e altura das plantas desramadas, proporcionalmente à intensidade de desrama, especialmente com remoção superior a $25 \%$ da altura da copa viva. Monte et al. (2009), avaliando o crescimento de Eucalyptus grandis aos 93 meses de idade, em Abaeté-MG, submetido a diferentes intensidades e frequências de desrama artificial, concluíram que a desrama não causou prejuízo ao crescimento do eucalipto, devendose evitar remoção superior a $60 \%$ da biomassa foliar.

Nos sistemas silvipastoris, é importante proporcionar às plantas de eucalipto condições para rápido crescimento, visando diminuir o tempo de entrada de animais no sistema, otimizando o uso da área. Plantas com altura inferior a $1,82 \mathrm{~m}$ tiveram danos severos com o pastejo de bovinos, em razão do pisoteio em mudas menores e da quebra de ramos laterais médios e superiores do eucalipto, ao se apoiarem sobre as árvores (Varella \& Saibro, 1999). Segundo Garcia et al. (2010), 2,5 m vem sendo considerada pelos pesquisadores a altura minima para que os animais possam pastejar na área sem que haja danos severos às plantas.

Apesar de a intensidade de desrama aplicada nos tratamentos estar dentro da faixa recomendada por vários autores (Polli et al., 2006; Monte et al., 2009; Garcia et al., 2010), notou-se a redução no crescimento das plantas, talvez em função da pouca idade destas no momento da desrama, apenas 10 meses após o transplantio. Pulrolnik et al. (2005) recomendam aplicar a primeira intervenção de desrama por volta dos 20 meses após o plantio. Ao antecipar a desrama, o crescimento das plantas pode reduzir, em razão da remoção intensa de galhos vivos da copa da árvore e, consequentemente, da área foliar. Essa remoção drástica de ramos das plantas implica a retirada de folhas da porção mediana da copa, e isso pode ter levado à redução no crescimento das plantas, conforme observado por Pires et al. (2002) e Pinkard et al. (2003). Desse modo, a definição adequada da intensidade da desrama evita comprometer o crescimento das plantas, além de facilitar as operações de controle de plantas daninhas.

Pulrolnik et al. (2005), avaliando a capacidade de crescimento de plantas de um clone de Eucalyptus grandis, em resposta à aplicação de diferentes intensidades e idades de aplicação de desrama, observaram recuperação no crescimento em diâmetro das plantas. Essa recuperação ocorre pelo fato de as plantas desramadas investirem primeiramente na recuperação da copa e, posteriormente, retomarem o crescimento.

A desrama precoce visando facilitar a aplicação do herbicida deve ser vista com cautela, uma vez que, mesmo com apenas 10\% de desrama, aos 640 DAA, ainda se observaram efeitos negativos, embora haja tendência de recuperação do crescimento das plantas, que pode, ou não, ser confirmada em avaliações futuras. Para essa decisão, devese levar em consideração que uma aplicação de herbicida mal feita pode levar a danos maiores (Tuffi Santos et al., 2010).

Conclui-se que o tipo de capina não influenciou o crescimento inicial do eucalipto. A desrama precoce facilita a aplicação de glyphosate, porém causa redução no crescimento inicial das plantas.

\section{LITERATURA CITADA}

ALMEIDA, M. L. Desrama artificial em clones de Eucalyptus grandis $\mathbf{x}$ E. urophylla com diferentes arquiteturas de copa. 2003. 119 f. Dissertação (Mestrado em Ciência Florestal) - Universidade Federal de Viçosa, Viçosa, MG, 2003. 
BEADLE, C. et al. Effect of pruning Acacia mangium on growth, form and heart rot. For. Ecol. Manag., v. 238, n. 3, p. 261-267, 2007.

CHIOVATO, M. G. et al. Diferentes densidades de plantas daninhas e métodos de controle nos componentes de produção do milho orgânico. Planta Daninha, v. 25, n. 2, p. 277-283, 2007.

ENDO, M.; MESA, G. V. Results of a pruning trial with Pinus patula in Colombia. IPEF Inter., v. 2, n. 1, p. 45-49, 1992.

GARCIA, R. et al. Sistemas silvipastoris: uma integração pasto, árvore e animal. In: OLIVEIRA NETO, S. N. et al. Sistema Agrossilvipastoril: integração lavoura, pecuária e floresta. Viçosa, MG: SIF, 2010. p. 123-165.

GOLFARI, L. Zoneamento ecológico do Estado de Minas Gerais. Belo Horizonte: Centro de Pesquisa Florestal da Região do Cerrado, 1975. 65 p.

LIMA, A. P. L. Aplicação de desrama em clone de Eucalyptus grandis em diferentes épocas e intensidade: efeitos sobre o crescimento e dinâmica de copa. 2003. 195 f. Tese (Doutorado em Ciência Florestal) - Universidade Federal de Viçosa, Viçosa, MG, 2003.

MACHADO, A. F. L. et al. Manejo integrado de plantas daninhas na cultura do eucalipto. In: FERREIRA, L. R. et al. Manejo integrado de plantas daninhas na cultura do eucalipto. Viçosa, MG: Universidade Federal de Viçosa, 2010. p. 15-37.

MONTE, M. A. et al. Crescimento de um clone de eucalipto submetido a desrama e desbaste. R. Árvore, v. 33, n. 5, p. 777-787, 2009.

PINKARD, E. A. et al. Physiological and growth responses related to pattern and severity of green pruning in young Eucalyptus globulus. For. Ecol. Manag., v. 182, n. 3, p. 231-245, 2003.
PIRES, B. M. et al. Crescimento de Eucalyptus grandis submetido a diferentes intensidades de desrama artificial na região de Dionísio, MG. Brasil Flor., v. 21, n. 73, p. 14-22, 2002.

PIRES, B. M. Efeito da desrama artificial no crescimento e qualidade da madeira de Eucalyptus grandis para serraria e fabricação de móveis. 2000. 96 f. Dissertação (Mestrado em Ciência Florestal) - Universidade Federal de Viçosa, Viçosa, MG, 2000.

POLLI, H. Q. et al. Qualidade da madeira em clone de Eucalyptus grandis w. hillexMaiden submetido a desrama artificial. R. Árvore, v. 30, n. 4, p. 557-566, 2006.

PULROLNIK, K. et al. Crescimento de plantas de clone de Eucalyptus grandis [hill ex maiden] submetidas a diferentes tratamentos de desrama artificial, na região de cerrado.

R. Árvore, v. 29, n. 4, p. 495-505, 2005.

SANTOS, R. R. et al. Avaliação de variedades de goiabeira em Monte Alegre do Sul (SP). Bragantia, v. 57, n. 1, p. 117-126, 1998.

TUFFI SANTOS, L. D. et al. Glyphosate em eucalipto: formas de contato e efeito do herbicida sobre a cultura. In: FERREIRA, L. R. et al. Manejo integrado de plantas daninhas na cultura do eucalipto. Viçosa, MG: Universidade Federal de Viçosa, 2010. p. 91-116.

TUFFI SANTOS, L. D. et al. Crescimento do eucalipto sob efeito da deriva de glyphosate. Planta Daninha, v. 25, n. 1, p. 133-137, 2007.

TUFFI SANTOS, L. D. et al. Crescimento e morfoanatomia foliar de eucalipto sob efeito de deriva do glyphosate. Planta Daninha, v. 23, n. 1, p. 133-142, 2005.

VARELLA, A. C.; SAIBRO, J. C. Uso de bovinos e de ovinos como agentes de controle da vegetação nativa sob três populações de eucalipto. R. Bras. Zootec., v. 28, n. 1, p. 30-34, 1999. 